\title{
Uma proposta para a leitura crítica dos videogames
}

Fabiano Andrade Curi

Jornalista. Mestre em Comunicação pela University of Westminster, de Londres, e especialista em Gestão de Processos Comunicacionais

pela Escola de Comunicações e Artes da Universidade de São Paulo.

E-mail: f.curi@uol.com.br

Os últimos quinze anos foram marcados por um aumento considerável do comércio de microcomputadores no mundo todo. A tal ferramenta corporativa tornou-se um bem bastante comum nos lares da classe média, pois a variedade dos programas para computadores abriu um leque de opções que permite aos usuários novas formas de comunicação, trabalho e entretenimento.

Este mercado que se expande vem sendo explorado por antigos e novos agentes da indústria cultural com volumosos aportes financeiros direcionados para as mídias digitais. Emergem, assim, alguns produtos de comunicação novos que ainda são pouco estudados, como o videogame. Localizar os videogames no mesmo espaço ocupado por meios de comunicação tradicionais pode ser visto com ceticismo por alguns, mas devemos considerar que muitos desses jogos eletrônicos estão em uma etapa inicial de seu desenvolvimento. Ainda que exista desde a década de 1960, nos últimos anos esse tipo de entretenimento eletrônico entrou em convergência com os meios de comunicação. Desse modo, jogadores podem trocar mensagens de texto e de voz, compartilhar arquivos eletrônicos e utilizar a internet. Isso sem considerar que os consoles que outrora apenas faziam funcionar os jogos, hoje permitem a reprodução de vídeos e músicas em diversas plataformas digitais. Os novos jogadores não usam apenas um joystick, mas também teclados, fones de ouvido, microfones e programas de comunicação que os colocam interconectados em ambientes de entretenimento e de comunicação. Além disso, mecanismos portáteis para jogos oferecem funções de telefonia, de leitura e edição de textos eletrônicos e de conexão em redes audiovisuais.

Essa complexificação dos jogos passa ao largo de estudos acadêmicos, desconsiderados como fenômeno cultural e comunicacional por diversos motivos. O principal deles é o fato de o jogo estar atrelado ao entretenimento, de ser lúdico, sem seriedade. $\mathrm{O}$ videogame, assim como outros meios de comunicação, tem de passar por uma fase de legitimação.

Embora haja ainda um desprezo em relação a algumas linguagens dos meios de comunicação, principalmente àqueles que são direcionados para a 
diversão de um público mais jovem, é inegável o crescimento desse mercado de entretenimento, o que significa acesso cada vez maior ao universo dos filmes, videogames e produtos voltados para o lazer. Isso quer dizer que as narrativas, formatos, personagens e conteúdos desses produtos são parte significativa e freqüente na rotina de gerações que crescem cercadas por novas formas de comunicação. Por isso, é importante um acompanhamento mais próximo do que acontece nesses jogos, quais são seus elementos, suas estruturas e suas origens, que tipo de ideologia está por trás e quais são os interesses ali envolvidos. Nada mais lógico do que desenvolver um olhar mais crítico acerca dos videogames e nada mais apropriado do que a escola assumir esse papel como espaço de debates e de orientação.

Como veremos na próxima parte deste texto, propostas de projetos para a leitura crítica dos meios de comunicação dentro de ambientes de ensino são extremamente importantes e pertinentes em sociedades estruturadas por intensa mediatização, dependentes, assim, da discussão sobre a mediação.

\section{O CRESCIMENTO DO MERCADO DE VIDEOGAMES}

A escolha do videogame como base para este texto se dá pelo fato de, como já foi dito, os jogos eletrônicos (em computadores ou consoles) serem muito jogados e pouco estudados. Quando se fala em educação para os meios, boa

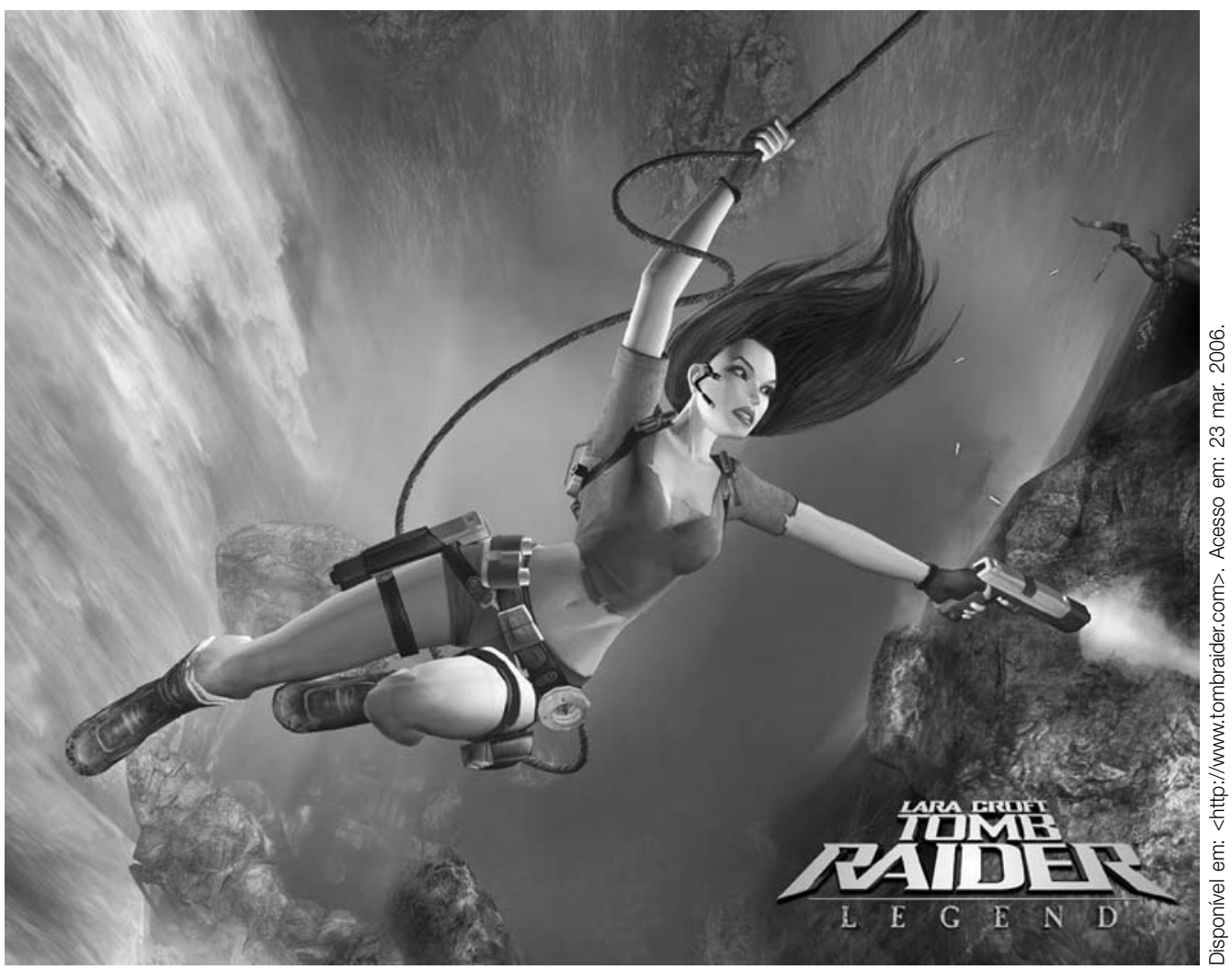

Lara Croft, a protagonista da série de jogos Tomb Raider, que ganhou duas versões para o cinema. 
parte das pesquisas enfoca a televisão, principalmente na América Latina, onde ela se apresenta como o meio de comunicação mais popular e de maior impacto, seja nas elites, seja nas classes subalternas. Encontramos também pesquisas sobre rádio e, em alguns casos, voltadas para os meios impressos. Atualmente, a internet, que extrapola os conceitos tradicionais de meio de comunicação de massa, atrai muitos estudos nessa área e, por extensão, também àqueles relacionados à educação.

O videogame, por sua vez, vem sendo jogado por adultos, jovens e crianças há mais de três décadas, mas pouco se fala dele dentro das escolas e nos estudos de comunicação. Se a televisão ainda é estereotipada como uma caixa idiota ${ }^{1}$ por muitos educadores e instituições de ensino, a imagem que se faz desses jogos não é nada melhor. São negligenciados como puro entretenimento que em nada colabora com o processo de aprendizagem do aluno. Pelo contrário, são citados como alienadores, violentos, viciadores, recebendo toda sorte de adjetivação negativa.

Contudo, o mercado de jogos eletrônicos vem crescendo bastante nos últimos anos. Se os videogames não despertam interesse acadêmico ou escolar, eles atraem bastante os investimentos de conglomerados de comunicação, gigantes como SEGA, Nintendo, Microsoft, Nokia, Sony, Disney e muitos outros. De acordo com um levantamento do mercado de entretenimento feito pela consultoria PriceWaterhouse, o Global Entertainment and Media Outlook - 2004/2008², a indústria de entretenimento e mídia deve ter um crescimento de $6,3 \%$ ao ano, atingindo um montante movimentado de 1,7 trilhão de dólares em 2008. Em 2003, as cifras chegaram a 1,2 trilhão de dólares. O videogame é o setor que promete o maior crescimento: $20,1 \%$ ao ano nos próximos três anos, com previsão de girar 55,6 bilhões de dólares em 2008.

$\mathrm{O}$ crescimento do mercado de videogames é proporcional à complexidade de seus enredos. Muitos dos jogos atuais não são baseados em alguns poucos movimentos mecanizados como os seus predecessores. Hoje, o jogador enfrenta desafios extremamente sofisticados, com incontáveis possibilidades de movimentos, decisões e conseqüências, tudo isso em um ambiente graficamente elaborado. Além disso, por meio das redes de computadores, os jogadores podem enfrentar outras pessoas, e não apenas a máquina, como faziam antigamente.

As possibilidades oferecidas por esses jogos os fizeram entrar definitivamente na indústria do entretenimento, demonstrando laços estreitos como outros meios de comunicação. O cinema é um exemplo. Muitos filmes tiveram adaptações para jogos, como O Resgate do Soldado Ryan, Matrix, O Exterminador do Futuro, Alien, Predador, 007 e Guerra nas Estrelas. Outros saíram de jogos, como Tomb Raider e Mortal Kombat. Além disso, alguns videogames são subprodutos de séries literárias de sucesso e foram ganhando espaço em outros meios de comunicação; casos de O Senhor dos Anéis e Harry Potter. Como se não bastasse, programas televisivos têm seus títulos estampados nas caixas de jogos. Arquivo $X$, CSI, Os Simpson, Big Brother e Show do Milhão são alguns exemplos.

Os jogos também exploram personalidades esportivas, que não deixam de ser midiáticas. Os principais nomes do futebol, do basquete, do beisebol, do
1. OROZCO GÓMEZ, Guilhermo. Professores e meios de comunicação: desafios e estereótipos. Revista Comunicação \& Educação, São Paulo: CCA/ECA-USP/ Moderna, n. 10, set./dez. 1997, p. 63.

2. GLOBAL Entertainment and Media Outlook - 2004/2008. PriceWaterhouse. Disponível em: $<$ www.pwc.com/outlook>. Acesso em: 11 jul. 2004. 


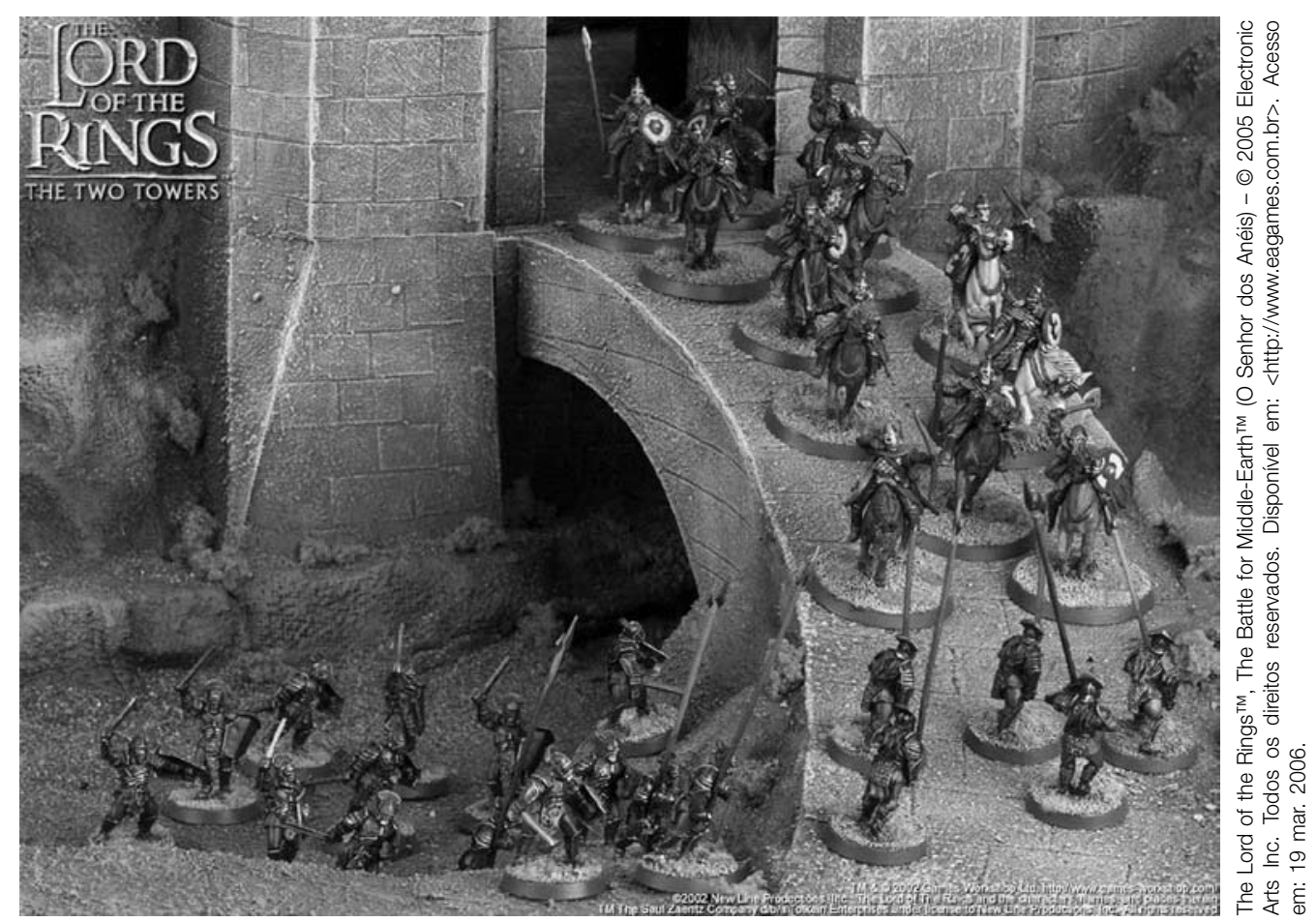

A série literária O Senhor dos Anéis originou filmes e títulos de jogos.

tênis, do golfe e da Fórmula 1 estão presentes nos computadores e consoles de milhões de jogadores espalhados pelo mundo. Dessa maneira, os jogos têm sido parte importante de toda uma indústria do entretenimento com fortes apelos visuais que impelem os jogadores a consumirem esses produtos. Trata-se de uma cultura do consumo que é uma cultura da comunicação visual ${ }^{3}$. Além disso, a complexidade dos jogos permite a inserção de conteúdo ideológico mais aprofundado. Como boa parte dos jogos é concebida nos Estados Unidos, os enredos são compatíveis com o posicionamento ideológico daquele país. Governo, instituições militares e empresas de lá estão dedicando especial atenção aos jogos. Daí a presença de tantos títulos com temáticas que envolvem militarismo, capitalismo, comunismo, terrorismo, sociedade de consumo, democracia confrontada e outros assuntos relacionados aos interesses hegemônicos norte-americanos.

Não há dúvidas de que esses jogos são populares entre os jovens. Em uma pesquisa realizada entre 1996 e 1997, com professores e alunos de 15 instituições de ensino da cidade de São Paulo, sendo 14 públicas, $70 \%$ dos docentes afirmaram não jogar. No lado dos alunos o número era inverso: $70 \%$ jogavam com regularidade ${ }^{4}$.

3. CANEVACCl, Massimo. Antropologia da comunicação visual. São Paulo: Brasiliense, 1990. p. 132.

4. CITELLI, Adílson. Comunicação e educação: a linguagem em movimento. São Paulo: Senac, 2000. p. 204
Obviamente, há um limitador econômico para se jogar. Os preços dos computadores, acessórios e dos próprios jogos excluem parte considerável de possíveis jogadores. Porém, já se nota um crescimento do número de micros entre as classes mais pobres e os jogos estão sendo barateados por alguns motivos: videogames antigos costumam ter preços menores do que os dos lançamentos; há um mercado de jogos piratas ativo nos grandes centros urbanos 
oferecendo produtos a valores bastante atraentes; e títulos que são distribuídos gratuitamente via internet, prática que tem recebido um combate absolutamente ineficaz por parte dos fabricantes.

O fato é que os jogos, junto de outros meios de comunicação, são parte importante da vida dos jovens e elementos de destaque na construção de sua visão de mundo. Não podemos simplesmente ignorar, negligenciar ou estereotipar os jogos dentro de um ambiente educacional ao partirmos da premissa de que "a leitura do mundo precede a leitura da palavra, daí que a posterior leitura não possa prescindir da continuidade da leitura daquele" ${ }^{5}$. Para Freire,

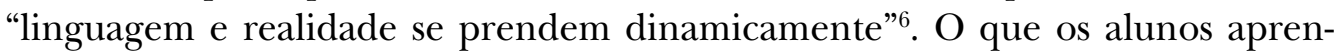
dem fora da escola tem importância em sua aprendizagem formal e isso deve ser levado em conta pelos educadores ${ }^{7}$. Os jogos trazem uma série de assuntos, valores, estereótipos e preconceitos que poderiam perfeitamente servir como base para discussões dentro das instituições de ensino. Dessa maneira, os jogos podem ser usados tanto para estimular uma leitura mais crítica dos meios de comunicação por parte dos alunos como para levar debates mais abrangentes e complexos para as salas de aula. Como diz Martín-Barbero ${ }^{8}$, muito do que constitui as classes populares ou faz parte de sua vida é rechaçado pelo discurso da Cultura (com C maiúsculo) e da educação, encontrando expressão na indústria cultural. Há de se descobrir, então, novas formas de participação e comunicação que falem o idioma dos alunos. Pois o aluno deve ter a possibilidade e a liberdade de expressar o mundo e o seu mundo ${ }^{9}$.

Se os jogos ocupam consideravelmente as horas de lazer dos jovens e crianças, eles precisam estar presentes nas discussões em sala de aula com o objetivo de formar alunos mais críticos em relação aos temas que fazem parte de suas vidas. Os detalhes dos objetivos serão explicados a seguir.

\section{AMBIENTE COLABORATIVO}

Na proposta que está sendo apresentada, o objetivo principal é proporcionar aos alunos que jogam videogames uma leitura mais crítica de seu entretenimento, empregando conhecimentos adquiridos a partir de um processo dialógico em sala de aula. É fundamental que eles não encarem seus hábitos midiáticos como algo distante da escola, local que normalmente fica associado a conteúdos áridos, de pouca pertinência em seu dia-a-dia. O propósito primário é que esse aluno alargue seu repertório e venha a compreender melhor o seu entorno.

Podemos considerar um outro objetivo importante: a desmistificação dos jogos como vazios de sentido ou de entretenimento sem valor cultural, que se opõe ao conhecimento. Devemos evitar o predomínio das vertentes moralista e culturalista, sobre as quais nos fala Soares, tão presentes nos discursos acusatórios sobre os meios de comunicação por parte de educadores. É importante fortalecer o aspecto dialético, ou seja, "o estudo das relações entre os receptores e os meios de comunicação, com base em uma reflexão que leva o lugar sociopolítico-cultural em que se encontram receptores e produtores" ${ }^{\text {. }}$.
5. FREIRE, Paulo. A importância do ato de ler. São Paulo: Cortez, 1992 p. 19.

6. Ibid.

7. OROZCO GÓMEZ, GuiIhermo, op. cit., p. 63.

8. MARTÍN-BARBERO, Jesús. Dos meios às mediações: comunicação, cultura e hegemonia. Rio de Janeiro: UFRJ, 2001.

9. GUTIÉRREZ, Francisco. Linguagem total: uma pedagogia dos meios de comunicação. São Paulo: Summus, 1978. p. 32.

10. SOARES, Ismar de Oliveira. Metodologia para comunicação e gestão comunicativa no Brasil e na América Latina. In: BACCEGA, Maria Aparecida (org.). Gestão de processos comunicacionais. São Paulo: Atlas, 2002. p. 118. 
Só assim, como diz Soares, podemos criar um ecossistema comunicacional. Essa nova postura acaba acarretando um ambiente colaborativo entre os diferentes grupos de uma instituição de ensino, principalmente aproximando os universos de professores e alunos.

Além desses objetivos apresentados, é essencial considerar que tal proposta possa encontrar espaços em instituições de ensino, uma vez que o problema aqui apresentado não é apenas indicado para um tipo específico de ambiente educacional e, desse modo, a multiplicação de projetos dessa natureza se faz necessária. Afinal, está se formando em amplas camadas da população um novo tipo de sensorium, "que antes vê e ouve do que lê"11.

Por último, mas não menos importante, a aceitação de videogames no ambiente escolar pode abrir portas para a utilização de outros meios nas práticas pedagógicas. Se a resistência ao uso dos jogos ceder, é possível que outros meios até mais tradicionais encontrem espaço dentro da sala de aula sem ficarem restritos a um uso meramente auxiliar por parte dos professores.

\section{INSTRUMENTOS PARA A REFLEXÃO}

Esta proposta pode ser resumida como um estímulo ao estabelecimento de canais dialógicos envolvendo alunos, professores e instituição com o intuito de incentivar a reflexão. Não é simples, pois, conforme afirma Bosi, o processo reflexivo exige "um alto grau de tomada de consciência da vida em si que começa na recusa do estabelecido, na suspensão da validade mundana" ${ }^{2}$.

Essa indicação de intervenção parte da afirmação de que o homem "vive e trabalha numa pequena parte da superfície da Terra, move-se num círculo restrito e, das coisas que conhece, conhece intimamente apenas umas poucas"13. A visão que extrapola a rotina dessa pessoa é recebida, na maioria das vezes, por meio da mídia. Portanto, é imprescindível que o homem saiba ler o que se passa na mídia para que possa entender melhor o seu mundo.

Para tal, temos na educação um importante instrumento que o ajuda a refletir sobre o que se passa a sua volta. Os estudantes de hoje, cada vez mais urbanos e expostos ao rádio, à televisão, às redes de computadores e aos videogames, encontram na escola leituras de mundo restritas ao livro e à fala do professor, pois a filtragem do que acontece na aula é feita pelo professor e, por isso, meios de comunicação só estão presentes como auxiliadores, jamais

1. CITELLI Adílson, op. cit., p. 149.

12. BOSI, Ecléa. A opinião e o estereótipo. Contexto, n. 2, p. 98, mar. 1977.

13. LIPPMANN, Walter. Estereótipos. In: STEINBERG, C. H. (org.). Meios de comunicação de massa. São Paulo: Cultrix, 1980. p. 149.

14. OROZCO GÓMEZ, Guilhermo, op. cit., p. 65. como fontes de discussão. Ainda que haja uma colaboração do aluno, ele pouco consegue modificar esse formato. Contudo, os processos de comunicação e aprendizagem não têm lugar na emissão ou no ensino, mas na recepção ou na resposta que dão os estudantes ao estímulo original, ou seja, "a aprendizagem não se define no professor e sim no aluno"14.

Fatores como poder aquisitivo do alunato ou a localização geográfica da instituição de ensino são importantes e variam de um ambiente educacional para outro, mas acreditamos ser possível afirmar que esse é um problema da escola. E esse problema tende a se agravar, pois passamos por um momento singular 
no qual as novas gerações crescem ao lado da rapidíssima evolução das mídias digitais, enquanto as mais antigas penam para entendê-las. Desse modo, fica claro um aumento da distância entre os discursos de educadores e educandos. Essa separação incorre no risco de formar gerações hábeis na operação das novas tecnologias de comunicação, porém limitadas na leitura destas.

Torna-se necessário, assim, o estudo desses meios de comunicação em ambientes educacionais, suas possibilidades e limitações. Para que isso aconteça de forma satisfatória, é importante conhecer as partes envolvidas, o equipamento disponível e, principalmente, os conteúdos apresentados pelos meios de comunicação. Abre-se um campo novo para profissionais que tenham a visão abrangente desses cenários e que apresentem propostas renovadoras e compatíveis com a contemporaneidade na educação.

Resumo: O objetivo do texto é discutir as possibilidades do uso de videogames em ambientes educacionais. Com temáticas complexas inseridas em jogos cada vez mais elaborados graficamente e com narrativas ricas, cabe um novo olhar sobre esse tipo de entretenimento, responsável por um mercado crescente mundialmente. Enquanto os alunos jogam com freqüência em casa ou em LAN houses, esses jogos são absolutamente negligenciados dentro das instituições de ensino. A proposta, nesse caso, é levar os jogos à sala de aula como fonte de discussão para algumas disciplinas.

Palavras-chave: videogame, educação, leitura crítica dos meios.
Abstract: The goal of the article is to discuss the possibilities of using videogames in educational environments. With complex issues inserted in games that present more and more graphically elaborated visual and enriched narratives, a new look is asked over this kind of entertainment, responsible for a growing global market. If in one hand students play frequently at home or in LAN houses, in the other these games are absolutely neglected inside educational institutions. The proposal, in this case, is to bring the games to the school classes as a matter for the discussion for some disciplines.

Keywords: videogame, education, media literacy. 